\title{
Copulas, credit portfolios, and the broken heart syndrome
}

\author{
An Interview with David X. Li
}

https://doi.org/10.1515/demo-2018-0007

Received January 15, 2018; accepted May 2, 2018

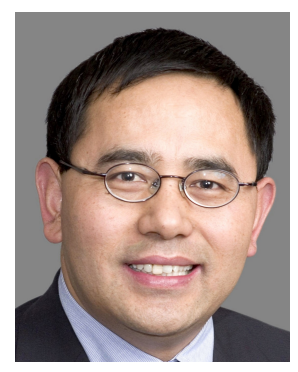

David X. Li is professor of Finance at the Shanghai Advanced Institute of Finance (SAIF). For more than two decades, he worked at leading financial institutions in the areas of product development, risk management, asset/liability management, and investment analytics. He was the chief risk officer for China International Capital Corporation (CICC) Ltd, head of credit derivative research and analytics at Citigroup and Barclays Capital, and head of modeling for AIG Investments.

David has a PhD degree in Statistics from the University of Waterloo, Masters degrees in Economics, Finance, and Actuarial Science, and a Bachelor's degree in Mathematics. David is currently an Associate Editor for the North American Actuarial Journal, an adjunct professor at the University of Waterloo, a senior research fellow at Global Risk Institute in Toronto, and a senior advisor to the Risk Management Institute at the National University of Singapore. David was one of the pioneers in credit derivatives. His seminal work of using copula functions for credit portfolio modeling has been widely cited by academic research, broadly used by practitioners for credit portfolio trading, risk management and rating, and well covered by the media (Wall Street Journal, Financial Times, Nikkei, and CBC News).

The seventh interview of our series is an in-depth discussion about the origin, use, and criticism of copula models in portfolio default risk modeling. Mathematical finance was among the first fields to adopt copula techniques, but it was the fast growth of the market for credit derivatives that boosted research activity on copulas, particularly on high-dimensional families and factor models. A seminal paper - introducing copula techniques to model a vector of default times - was published by David X. Li, see [11]. With the article "The formula that killed Wall Street” by Felix Salmon in WIRED Magazine, February 23, 2009, republished in [18], David and his model received world-wide media coverage.

In the following, our questions to David X. Li are typeset in bold-face.

\section{Educational background}

\section{Would you please tell us something about your educational background?}

I grew up during the Cultural Revolution Period (1966-1976) in a rural area of China and had a sporadic early education. Certain subjects, such as Mathematics and Physics, might be taught well by teachers who happened to be "intellectuals" expelled from a city environment to the countryside. Other subjects were often taught by high school, or 2-year college, graduates who barely learned anything serious in their own studies.

\footnotetext{
Giovanni Puccetti: Dipartimento di Economia, Management e Metodi Quantitativi, Università di Milano, Italy. *Corresponding Author: Matthias Scherer: Lehrstuhl für Finanzmathematik, Technische Universität München, Germany. E-mail: scherer@tum.de
} 
I majored in Mathematics at college, where I learned the basics of pure mathematics. I enjoyed mathematics in high school, but pure mathematics at university level wasn't very appealing to me. I found more applied subjects, such as probability and statistics, more interesting. After graduating from college, I switched to studying Economics at Nankai University. At that time, China started focusing on its economic development and opening up to the world. As a result, the country was eager to train a group of professional managers and economists. I left the country to study for an MBA degree in Finance at Université Laval in Quebec City in 1987, originally intending to return to China.

At Université Laval I learned all the basics of modern finance and became keenly interested in the subject. Many of the professors were trained at top schools in the US or Europe. Very quickly I found that my mathematical skills were not good enough to read the latest research papers. I decided to study more Mathematics and Statistics at the University of Waterloo. I also picked up Actuarial Science and got my associate designation from the Society of Actuaries (ASA) by passing ten written exams. I ended up with five degrees in five different subjects. To a certain extent, I had always been playing a catch up when switching from one subject to another.

\section{Who was particularly influential for your education?}

At the University of Waterloo I took classes at all levels in different areas: Finance, Actuarial Science, and Statistics. Waterloo has one of the best Actuarial Science programs in the world. I took classes in Actuarial Science with Professors Harry Panjer, Gordon Wilmot, Steve Brown, Allen Brender, and Keith Sharp. I took Professor Phelim Boyle's Finance class at the PhD level. I learned most of my statistics skills from a group of great statisticians: Professors Jeff Wu, David Sprott, Don McLeish, Mary Thompson, Bovas Abraham, and Chris Small.

In my $\mathrm{PhD}$ thesis I extended estimating function theory to Bayesian statistics and then applied it to credibility theory in actuarial science. I got a chance to work very closely with Professor Vidyadhar Godambe ${ }^{1}$ who introduced the concept of estimating functions. At that time, he had already retired, but still came to the office every day. For the entire summer of 1994, I sat in his office a few times a week to learn and discuss with him. What a great mind! We had many visitors in Waterloo: Hans Bühlmann and Paul Embrechts, see [3], visited frequently, along with David Cox, Arnold Zellner, and other top statisticians.

I left Waterloo for a tenure-track position at the University of Manitoba, one year before I completed my $\mathrm{PhD}$ studies, and went to work in the financial industry immediately after my graduation. Consequently, I never had a chance to spend more time on academic research. This explains, why I now decided to go back to school to teach and to do research after 23 years of working in the industry.

My supervisors, Professor Phelim Boyle (see Fig. 1) and Professor Harry Panjer (see Fig. 2), had a particular impact on me. Harry was always encouraging to students and open-minded. When we discussed about the topic of my $\mathrm{PhD}$ thesis, Harry was very flexible and let me decide. It was also a lot of fun to work with him. He sometimes took us for a flight on his airplane and we flew over his farm. Phelim was very inspirational and always very nice to graduate students. He encouraged me to study more finance and I was totally impressed by his dedication to and passion for research. He placed a lot of emphasis on using intuition and effective explanation in addition to employing rigorous quantitative techniques.

\section{Financial engineering in the credit market}

\section{What was your first employment in the financial industry?}

Upon graduation in 1995, I joined the Royal Bank of Canada (RBC) as a senior analyst in its risk management department. I was working on market risk for equity and foreign exchange (FX) businesses. I also worked on credit exposure calculation. At that time we didn't use the name value-at-risk, but "dollar-at-risk."

1 An obituary was published in the IMS Bulletin by Mary Thompson, see http://bulletin.imstat.org/2016/09/obituary-v-pgodambe-1926-2016/ 


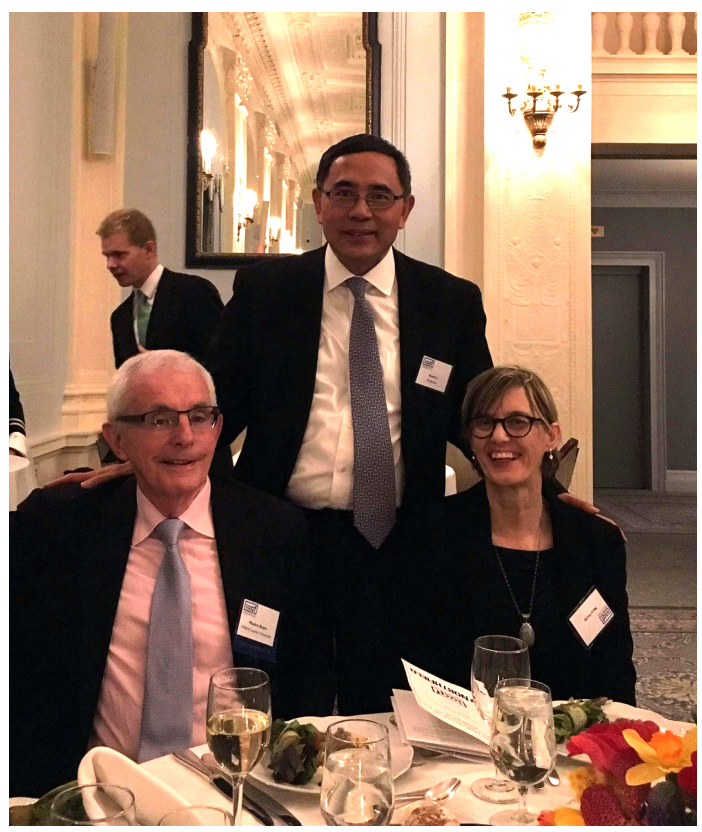

Figure 1: Phelim Boyle, David Li, and Mary Hardy in 2016.

Immediately I realized that a lot of practical work required quantification. But sometimes quantitative concepts were used very loosely. For example, credit exposure was calculated as the maximum of potential future losses at different points in time in the future. At each time point, it was calculated as the $95^{\text {th }}$ percentile potential loss. Then, the final credit exposure was still called the $95^{\text {th }}$ percentile credit exposure. You really didn't know to which probability space (or distribution) this $95^{\text {th }}$ percentile was related to.

That was the beginning of a period in which the derivative ${ }^{2}$ business in the financial industry grew rapidly. It was wonderful to learn about all these new products and their pricing models. With the training from five academic degrees, I felt that I was one of the most prepared persons in the industry, but I still needed to learn the market conventions and I had to develop implementation skills in programming languages such as $\mathrm{C} / \mathrm{C}++$ and VBA. A strong mathematical and statistical education definitely provided me the foundation to work on a number of applied problems. Finance and Actuarial Science training were very useful, too, since they helped to formulate a practical problem into a mathematical model. Different $\mathrm{PhD}$ graduates had different "nails" at hand when they came to work in the industry. Sometimes, it is a narrow view trying to solve a problem using only the "nails" at hand, since there might be better tools available for a specific problem. It was an exciting period, as there were a lot of product innovations, new ideas, and the interaction between industry and academia was very fluent.

I used the opportunity to learn as much as I could from professors and more experienced practitioners in the industry. For example, John Hull and Alan White were very active and gave seminars at the University of Toronto. At RBC we had Professor Durrell Duffie as a consultant for credit risk, that was the first time I got to know him. Subsequently, I consulted him from time to time on credit risk and credit derivative pricing.

How was the mood among quantitative analysts in the pre-crisis days? What role did stochastic models play?

Before the financial crisis, most derivative pricing models had become "time-tested" and were available in mature forms - with the exception of models for credit derivatives. The credit derivative market was still at

2 Editorial remark: A derivative is a contract whose value depends on the price of an underlying asset. Depending on the complexity of the stochastic model for the underlying and the contract details, finding the price of a derivative is a difficult mathematical task. 
the forefront of innovation, with products such as pay-as-you-go (PAUG) CDS contracts for ABS bonds, CDX indices, $\mathrm{CDX}$ tranches, CDS options, $\mathrm{ABX}$ indices, $\mathrm{ABX}$ tranches, and option products for $\mathrm{CDO} \mathrm{s}^{3}$, etc. This attracted a group of quants who traditionally worked with interest rates. They took a close look at the status quo of credit-portfolio modeling and felt that credit-portfolio models lacked "dynamics," expressed in terms of stochastic processes as typically used for interest-rate modeling. There was a lot of effort to come up with new models to replace the Gaussian-copula framework. With the exception of certain option products for portfolio, most of these new models were not broadly accepted in the industry.

A few years before the financial crisis I had switched my attention to mortgages, mainly subprime, and the modeling of new products such as PAUG CDS on ABS bonds, ABS CDOs, and ABX tranches. I didn't know much about mortgages and had to start from scratch by building a team. I first interviewed some experienced mortgage modelers. But mortgage modeling at that time focused on agency mortgages, in which credit risk modeling was not required, as Fed agencies provided a guarantee for the default risk and the focus was mainly on interest-rate modeling. I also found that most mortgage modelers didn't have a strong statistical background, especially no training in survival analysis. I formed a small team with quants already in the firm having a strong statistical background and added a few young $\mathrm{PhD}$ graduates, capable students from Stanford and Columbia, to investigate the problem from scratch. We started from tabulation using multiple decrement theory and moved to dynamic competing risk models. The modeling involved three stages: first, we needed to do fundamental modeling for mortgages for both prepayment and default risks. Then we needed to model the waterfall structures in the ABS bonds, since these bonds are in tranches, already securitized. Finally, we needed to model the derivative features either with PAUG CDS on ABS bonds or with ABS CDOs which are more like a CDO squared.

It didn't take us long to understand that newly issued subprime mortgages had default rates of 3 to 5 times, or even 6 to 7 times, higher than the mortgages issued in the early days. If this trend continued, the ABX index bonds should be priced at 30 or 40 cents on a dollar, but they were still traded around par in the market at that time! Considering the potential loss that an ABS team could experience, our mood was pretty bad. But this knowledge was confined to a small group and the overall market was still ebullient. CDX, the North American credit index of 125 investment grade names, was pushed all the way down to 27 basis points before the Summer of 2006. Then, a one day 30\% price drop in March 2007 was a wake up call to everyone and for the next couple of years there was a lot of confusion around the value of these complicated securities. Having the best modelers did not imply the ability to get the message to the top and help the firm to avoid the crisis. Laurie Goodman was a long time, top-ranked-by-the-industry mortgage modeler at UBS, but UBS incurred one of the largest losses in subprime among all Wall Street firms during the financial crisis. It was quite a conundrum to mix the modeling of complicated securities with incentives to hide large losses, whether this is for large bonuses, fear of losing shareholder value, or simply the prospect of keeping one's own job.

\title{
3 The Gaussian copula model
}

\author{
Let's start from the beginning. What was the application you had in mind when you developed what \\ is nowadays known as the Gaussian copula model for credit portfolio defaults?
}

\footnotetext{
3 Editorial remark: A very basic credit derivative is the CDS contract. Essentially, it constitutes an insurance like contract, where premium payments are exchanged for a default compensation that is due if a reference bond defaults. The main task in pricing such contracts is to model the default time of the underlying bond (neglecting recovery-rate risk and interest-rate risk). If many such contracts are pooled, one speaks of a CDS index. CDX is the name for a family of tradable credit default swap indices in North America. The pricing problem becomes much more complicated if a pool of credits is "sliced into tranches," as done in case of a Collateralized Debt Obligation (CDO). The non-linear way of distributing the loss withing the credit portfolio to the different tranches of the pool requires a model for the dependence structure among the individual credits in order to price the tranches. For this modeling step, David X. Li pioneered the use of copulas. The acronym ABS stands for asset-backed security - a security collateralized by a pool of assets such as credit cards. The non-agency residential mortgage backed securities are also called ABS bonds.
} 
The intention was to solve practical problems for our sales and trading business in the financial products group at the Canadian Imperial Bank of Canada (CIBC) in the middle of the 90s. For example, we were worrying about the joint default of a reference credit and a counterparty in a single name CDS contract. More specifically, we might have a CDS with the Korean Development Bank as the reference asset and a Japanese bank as the counterparty, which occurred before the Asian crisis. In the emerging market credit derivative business in the period from 1996 to 1999 we already had small basket credit derivatives such as a first-todefault (FTD) and a second-to-default (STD) contract ${ }^{4}$. Cash CDO or more CBOs were already issued, and various credit linked notes were created.

How did you first discover copulas as a methodological tool? Is this somehow linked to your academic background in Actuarial Science?

I heard about copulas from my colleague Jacques Carrière, when both of us were teaching Actuarial Science at the University of Manitoba. He was doing a research project with Professor Jed (Edward) Frees and his then PhD student Emiliano Valdez at the University of Wisconsin, see [6]. Emiliano is now a professor of Actuarial Science at the University of Connecticut. The project was about the valuation of joint life annuity products by considering the broken heart syndrome. Traditionally for valuation actuaries take a couple's life contingencies as independent of each other: male policyholders follow male mortality tables, while female ones follow female mortality tables. But as a couple they live in the same house and travel together and they are exposed to a lot of common risks. When they get older, they depend on each other even more. The death of one spouse has a big impact on the other. Empirical studies show that the impact is even not symmetrical: the impact from a death of the wife has much larger impact on the life of the husband than vice versa. They did some empirical studies using data from Great West Life, found a positive correlation of survival times for couples, and studied the impact on the valuation of joint life annuity products using copulas. I was aware of this research from Jacques, but I didn't spend much time to learn more details then, as I was still trying to complete my $\mathrm{PhD}$ thesis on a totally different topic.

I initially spent a lot of time using the stochastic hazard rate model introduced by Duffie and Singleton [2] and applied it to CDO pricing, but I couldn't get the model to fit the market. In addition, traders didn't like models with a large number of parameters and the computational demand was tremendous, even with a Window NT 3.0 environment. I started to look for a "simple" solution. That was when I asked Emiliano to send me his working paper with Jed and Jacques, see [6]. He sent me the working paper [7] (by fax!) while I was working for CIBC Financial Products Group in New York. At that time, Roger Nelsen, see [4], was about to publish his book [16] on copulas. I reached out to him for a preprint and promised to buy a copy when the book got published. I hope the reference to his book in my paper helped him to sell more copies. Professor Paul Embrechts (see Fig. 3) gave a talk at Columbia University in 1999 on copulas with applications in risk management, see [5]. I approached him and told Paul that I had been using copulas for the last few years. He was surprised and asked me what I used copulas for. I mainly used them for the pricing of credit derivatives. Shaun Wang [19] wrote a research report for the Casualty Society of Actuaries (CAS), an application to capital allocation, which I also read. I spent quite some time in the New York Public Library to read some conference proceedings on copulas, especially articles on the construction of copulas using extreme value distributions.

You mentioned that you wrote your PhD on a "totally different topic.” Would you mind explaining it in a few sentences?

I had taken a lot of classes in statistics at the University of Waterloo, but never did any research in statistics. Also, I was expecting to work in the industry after my $\mathrm{PhD}$ studies, and writing a $\mathrm{PhD}$ thesis could be the last chance for me to do a research project using statistics. So, for my PhD topic I chose to work on estimating functions with applications to credibility theory.

4 Editorial remark: A first-to-default (second-to-default) derivative is similar to a CDS contract. Again, an insurance premium is exchanged against potential default compensation. The difference is the definition of the default event, which is now the first (second) default event within a pool of credits. Consequently, the dependence structure within the default times of the entities in the pool needs to be modeled. 


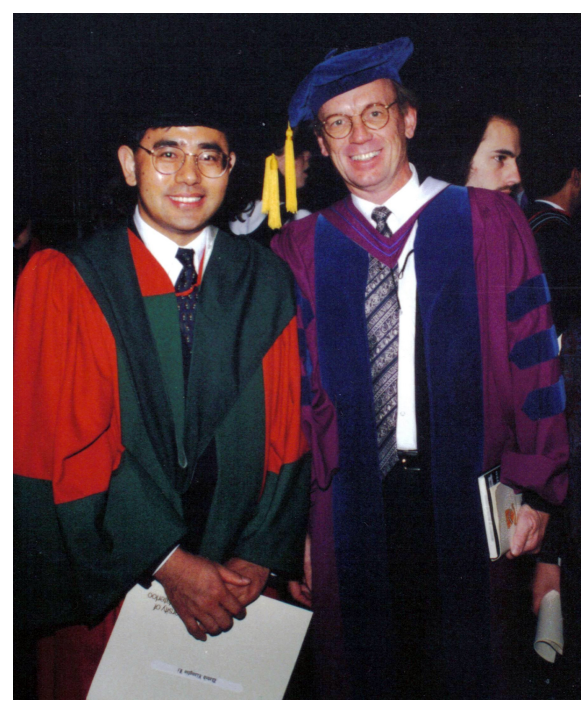

Figure 2: David Li and Harry Panjer at David Li’s PhD graduation ceremony in 1995.

The theory of estimating functions, see [8], is a generalized estimating method which unifies estimating methods such as maximum likelihood estimation (MLE) or the least squares (LS) method. An estimating function is a function of both data or observations and parameters to be estimated. For example, a score function used in MLE is an estimating function. In spirit, it is similar to the generalized method of moments (GMM) for which Lars Hansen, see [9], won a Nobel prize in economics. I was working on the extension of the framework by adding prior information (still in terms of estimating functions) and then applied it to credibility theory. When I was working at the University of Manitoba, I worked with Professor Harry Turtle, see [12], to expand one subsection in my $\mathrm{PhD}$ thesis and published a paper on GARCH parameter estimation using the theory of estimating functions. I still wish that there were more interactions between researchers in these two areas.

You mentioned Paul Embrechts. His paper [5] had a considerable impact on dependence modeling in Quantitative Risk Management. Was it also relevant to you?

Paul gave a talk at the Columbia-JAFEE Conference on the Mathematics of Finance on March 28, 1999 with the title Insurance Analytics: Actuarial Tools in Financial Risk Management. In this presentation Paul talked about his research paper with Alex McNeil and Daniel Straumann Correlation and Dependence in Risk Management: Properties and Pitfalls. This might have been the first occasion that the concept of copulas was presented to a large audience in the financial industry. At that time, I was writing the paper [11] which was lately published in the Journal of Fixed Income. But most of the work was already done during 1996-1998, while I was working at CIBC in its Financial Products Group. The paper of Paul and his coauthors addresses much broader issues around correlation, which had and still has a great impact on the whole industry. I, personally, was simply focusing on credit-portfolio modeling at that time. Paul is a prolific researcher with research topics across different areas. He is also very inspiring and helpful to others. He is one of the best people to combine academic research with industry needs. I have always looked up to him for advice and help.

In your famous paper [11] you mention various copula families. In your opinion, why did the financial industry end up using precisely the Gaussian copula?

This can be traced back to the modeling of a firm's asset returns. As in Merton's seminal work, see [15], the assets of a firm are modeled as a lognormal process, and hence, the returns as a normal process. But if you look at the problem purely from an engineering perspective: using a copula to create a joint distribution based on given marginals, you can, in theory, use many other copula functions. Actually, we studied various copulas on our trading desk such as the Frank copula and mixture copulas based on extreme value distributions. Once you control the correlation by having the same rank correlation, one can study the impact of different copulas. 


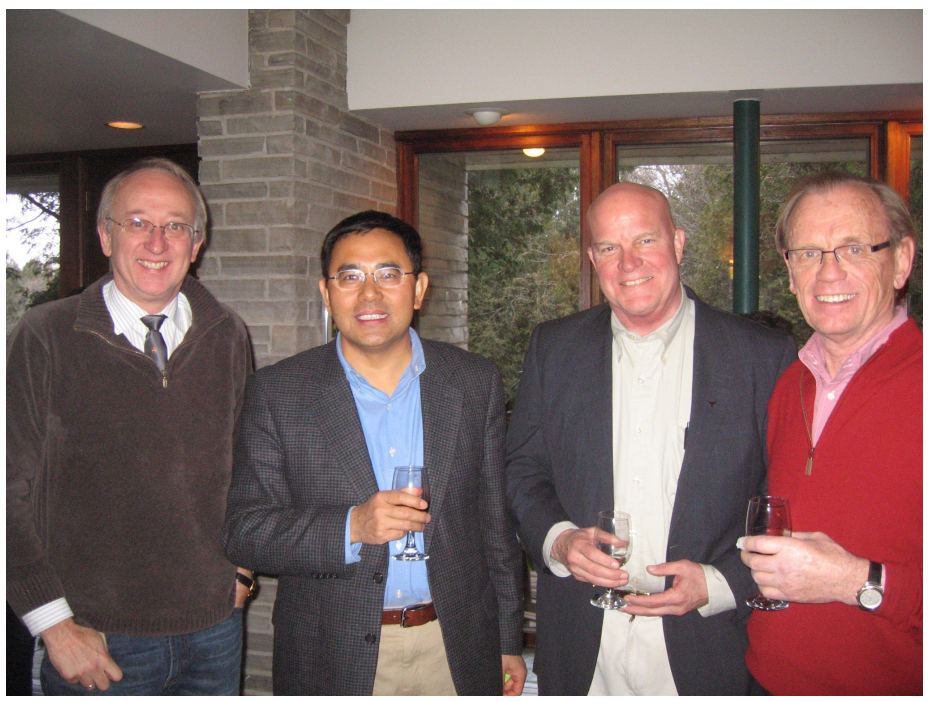

Figure 3: Paul Embrechts, David Li, Patrick L. Brockett, and Harry Panjer at Harry Panjer's retirement party in 2007.

I feel that the area had not come to the stage to differentiate the subtle difference that different copulas could create at the early stage of using copulas in credit-portfolio modeling. Also, we need to have some economic interpretation for the copula we chose and its parameters. I know quants from Lehman Brothers, see [13, 14], were pushing for the Student's t copula for a couple of years, but users found little difference between the Gaussian copula and the Student's t copula when it came to the valuation of CDO tranches.

In my paper, I listed a few copula families. The example for a CDS with a risky counterparty was based on a mixture copula, while the example for FTD pricing was based on the Gaussian copula. I wasn't specifically advocating the Gaussian copula, not to mention the "one factor Gaussian copula." What I presented was a general framework and the paper also established the link between the Gaussian copula and the one-period Merton model.

Market participants need a simple model to communicate with each other. People use implied volatility for option quotes with the understanding that we all use the Black-Scholes formula. We use the one-factor (or one parameter) Gaussian copula for CDX or ITRAXX tranche trading for the same reason. I feel that the Gaussian copula has become popular for both its economic interpretation and its simplicity, especially with a single correlation parameter.

Was (or is) there awareness in the industry that various commercial portfolio-default models give rise to the same dependence structure as provided by the Gaussian copula - mostly without mentioning it?

There were definitely people who might have used the concept, but might not know the concept of copulas. Joe Pimbley, who was working with Moody's in 1995, wrote a dozen-page note on how to build a dynamic model for joint defaults. In this note he had described all essential elements of a dynamic model for creditportfolio modeling: a stochastic interest rate model for the yield curve, a dynamic model for spreads, and embedded default into the process with "tests” for default at every time step. But it didn't specify how to model the default time, and to use asset returns for correlation.

Many of the credit-modeling papers were published during the period 1994-2000. Duffie and Singleton published their paper [2] as a working paper in 1994, and the final version in 1999. The Jarrow-Turnbull [10] paper was published in 1995. The KMV technical document by Vasicek was available around 1995. The CreditMetrics Technical Document by JP Morgan [1], CreditRisk+: Technical Documentation by CSFB [21], and CreditPortfolio View by McKinsey [22] were all published in 1997 and 1998.

As a practitioner in the credit area, I was keenly aware of the latest research developments and I spent a lot of time to digest the research, benefiting from direct contact to most of the authors. Professor Turnbulll was 
working for CIBC, first as a consultant and then as a full-time employee, when I was working for CIBC, where most of the ideas of applying the concept of copulas in credit were conceived, studied, and applied to solve practical problems in credit derivative pricing and trading, as well as in credit-portfolio modeling. Professor Turnbull was consulted frequently, and he might be one of the first academic people to whom I presented the idea of using copulas for credit portfolio modeling. I got to know Professor Duffie in 1995 and often met with him to get his advice or to learn about the latest developments in the academic world. In 2000 at the Society of Actuaries (SOA) 50-year anniversary meeting in San Francisco I, as an SOA Investment Section council member, organized a session on credit portfolio modeling and invited Chris Finger, one of the three authors for CreditMetrics, Tom Wilde, who was the main person behind CreditRisk+, and Tom Wilson, who created CreditPortfolioView at McKinsey, as panelists in the session. I knew that KMV, CreditMetrics, what Joe Pimbely implied in his note, were all based on the Gaussian copula, even though the copula concept was not used explicitly in their approaches. Explicitly linking these models to the Gaussian copula framework helped with the conceptual understanding of the model and possible extensions. In addition, it also helped with the efficient implementation. For example, the one-factor model based on conditional independence had substantially improved the computational speed of the Gaussian copula model.

When I joined the RiskMetrics Group (RMG) at the beginning of 1999, I told Chris Finger about the equivalence of the CreditMetrics approach and the Gaussian copula model. It took us two afternoons in front of a white board to go through the technical details. Actually, it was Chris Finger who strongly suggested me to write a paper about it. I wrote the paper and had it as one of the research papers at RMG, and made it available to the public. Chris sent the working paper to Micky Bahtia who called and suggested to submit it for publication as soon as possible.

I read and studied all the above approaches, but my major concern at that time was to solve practical problems that we were facing in credit derivative sales and trading. While each of the above approaches tackled credit problems from a different angle, they were not necessarily all ready to be used in practice for pricing and valuation. For example, CreditMetrics, KMV, and CreditPortfolioView are largely one period models with the intention to obtain the loss distribution over one period for credit-risk management or economic capital calculation.

The first conceptual challenge was to move away from this one period, or mainly one-year time horizon, which seemed to be used by rating agencies and many others in the credit-portfolio modeling area. But for the trading of credit derivatives we have to move away to cover the term structure of defaults. In practice, the term structure is important, as a firm does not in general default if it does not have a debt to mature. Before the Asian crisis one frequently traded name was the Korean Development Bank (KDB). When the Asian crisis just started, KDB credit spreads showed a clear humped shape, first increasing for the first two to three years, and then declining. It was the first time that I observed such an evidently humped term structure of credit spreads. The rationale in the market at that time was, that the Asian crisis just got started and no one knew when it would be the worst, which explained why the spread moved upward for the first two to three years. But on the long term, the market speculated, South Korea sovereign should still have good credit if it could overcome the difficulty in the next two to three years. Now it is all history and KDB credit performed afterwards almost exactly as traders had expected at the beginning of the crisis. So, I was trying to sort out the issue of how to incorporate the term structure of spreads. It didn't take too long for us to create a "credit curve" which is expressed as the term structure of hazard rates. The underlying variable is the survival time for each credit, and we describe it in a similar fashion as we do for the survival time of a human life as expressed in a mortality table. Once we use the survival time to describe default it is easy for us to price single name CDS. For some issues, such as the timing of default within a premium payment period, we simply used continuous approximations instead of what is called the JP Morgan approach or the Hull-White approach which assumed that default occurred at the end or in the middle of the premium payment period.

Of course, there were issues about recovery rates and recovery treatment assumptions. From a modeling perspective, I preferred the Duffie-Singleton approach about recovery treatment, as it provided more consistent results, especially when you dealt with forward starting transactions such as forward starting CDS. I wrote a paper on "Constructing a credit curve" and published it in a special report of the Risk Magazine in 1998, in which I introduced the "time-until-default" or survival time to model single name defaults and 
explained how to construct a credit curve based on market observables such as bond prices or asset-swap spreads. This might be one of the first papers on credit-curve construction. Once you constructed a credit curve for each name in a credit portfolio, you wished to have a joint distribution of survival times to describe the joint default properties for the credit portfolio. That was where copulas came into the picture.

Immediately we faced the issue "which copula to use?" and how we should deal with its parameters. That was when the CreditMetrics - Technical Document, see [1], was released and I also read Vasicek's handwritten notes on credit portfolio modeling back in 1995 or 1996. The link between the Gaussian copula and the Merton model was established, and immediately we had a meaning for the correlation parameters in the Gaussian copula: asset-return correlation. We used KMV or a simpler version, the CreditMetrics approach, for the asset return correlation based on an equity risk-factor model, and the empirical relationship between the asset size and idiosyncratic risk of a firm. The first application we had was on our single name CDS book, but with the consideration of counterparty risk. Pricing the first-to-default, the second-to-default, or CBOs became very easy using a copula. So, the Gaussian copula was chosen mainly due to the fact that we model asset returns as a normal distribution. In its original form, we could use different pair-wise correlation parameters in the correlation matrix instead of "one factor" or the one-parameter Gaussian copula model, which is a simplified correlation structure for trading. We spent a lot of time studying how to reduce the dimensionality in the correlation using various correlation structures or analytics such as principal axis analysis.

\section{The credit crisis of $2007+$}

\section{When did the financial industry receive the first warning signals on the Gaussian copula model? How did it react?}

In 2005 the Gaussian copula model had trouble calibrating to market prices, because of worries about auto industry defaults. The spread for the equity tranche became very high, and the model had difficulties to calibrate a base correlation for certain mezzanine tranches. In this situation, you needed to think about the cause of these issues. Was it a problem of the model or was the market pricing certain tranches not rationally? For example, European side ITRAXX didn't have the same issue with the worry of a few defaults in the auto industry like in the US, but it also had difficulties calibrating to the mezzanine tranches. I talked with one trader on the London side and suggested him to sell protection on the equity tranche and buy protection on mezzanine tranches. Within a few days he made more than USD 10 million; he suggested me that I should start an internal hedge fund!

In a new market, we need to be careful about the validity of the market or the model. For a fundamental market with simple instruments the traders as a group might have a collective rational opinion on the prices of traded instruments. But in a brand new market, traders might have challenges to provide rational quotes initially. For example, at the introduction of ITRAXX trading there were just a few large investments banks providing two-way quotes for ITRAXX tranches. Every morning, these few banks sent out to their customers a list of quotes with bid-ask spreads. One day a trader sent out his quote purposely to push the market in one direction, but with a larger spread. To his surprise, many other firms just followed his quotes with a move in the same direction.

We were using the one-factor Gaussian copula and base correlation for a while before we ran into the situation (briefly) in 2005 that we had a challenge calibrating it to the market. Many people were studying and introducing alternative models. But up to this date, I do not know that there is one agreed upon alternative model for credit portfolio modeling for trading purposes. The most common one is still based on the Gaussian copula and base correlation, but with some modifications such as random recovery rates.

Still, we need to take some fundamental reservations with respect to the Gaussian copula model. The common criticisms are tail independence, static dependence structure, or poor hedging performance. I would like to address each of the above points here.

Tail issues: As stated above, we use the Gaussian copula due to the fact that we model asset returns using Brownian motions. Almost all finance theory is based on the normal distribution. Using base correlation is 
one way to handle the problem of "not enough correlation / dependence" for senior tranches, which is linked to the fact that the Gaussian copula is tail independent. Base correlation is similar to the implied volatility concept, and volatility smiles or skews. To overcome tail independence, we could also see a mixture Gaussian copula model or a Gaussian copula model with random correlation, which is similar to a stochastic volatility model for option pricing.

Static dependence structure: This is a somewhat vague comment. In a copula model based on survivaltime distributions we describe each credit only by default or not. This is a simplified way to describe the evolution of credit quality, similar to dividing people into only "good" or "bad" ones. It has its dynamics, it might have too strong dynamics. For example, if you look at the correlation from a conditional perspective you would observe that the dependency might be too strong: conditional on one name default in one year, another name with a positive correlation with this name would have conditional hazard rate move high up very quickly, but it would take a long time for it to return to its original unconditional level under the Gaussian copula framework.

Many modelers feel that we have to write a stochastic diffusion equation to have a dynamic model. We could use a stochastic process to describe the hazard rate for each credit and introduce correlation at the level of the hazard-rate processes. That was the first approach I was trying to implement. Unfortunately, it didn't capture the market well in addition to all computational burden. It took me a while to understand this observation intuitively. You could think about a hazard rate as the "volatility" of a default event. It does not matter how strong the correlation structure is, that you introduce at the "volatility" level, the correlation on the default events is still pretty weak. Duffie and his $\mathrm{PhD}$ students have done some research in this area to enhance the stochastic hazard-rate model, by having a common driving factor in all individual hazard-rate processes, or by adding a jump process. This definitely helps to explain the real-world dynamics better. But the model is not parsimonious, since we need to have a lot of parameters, and these models are difficult to implement and to use in practice. How could we use this kind of models to manage hundreds of portfolio type trades on a daily basis?

There were a lot of these "second generation" credit-portfolio models between 2005 and 2008 and many of them originated from the interest-rate modeling area. In these models, the main focus is on the evolution of the total credit portfolio loss distribution, each credit's contribution is only on the initial term structure of the expected portfolio loss distribution. The loss distribution over a specific time period is only captured by the stochastic process from the total loss distribution. Few studies have been done on the shape and form of the loss distribution underlying these models. The dynamics of the individual credit contribution is basically fully lost with only a link to the expected portfolio loss distribution remaining.

How to hedge credit risk is still an area that requires more research. Do we hedge spread risk or default risk? There are few empirical studies on hedging performance of credit spread risk based on the Gaussian copula model, and the conclusion is not definitive. I might have missed something here, but I haven't read some comprehensive studies on this. Alex Reyfman wrote a research report while he was working for Bear Sterns. We did a lot of internal studies at Citi and Barclays and couldn't draw a definitive conclusion. The hedge against default events is even more complicated. For example, we studied the default hedging for a small basket problem such as a FTD. To have a perfect hedge of a 4-name FTD, we need to have trading instruments of all single name CDS, FTD of every two names, and FTD and STD of every three names. Also, it would take a very long time to test the hedging performance if you do not have a perfect hedge as indeed default by definition is a rare event.

I had been aware of all these issues while I was working as a practitioner in sales and trading of financial institutions and had done a lot of research with the team I was heading and the colleagues I was working with. We could point out more issues from a more technical perspective about the Gaussian copula model, but to find an alternative model to remediate these issues is much more challenging. I would like to see more academic research in this area.

From the outside, one could have the impression that the financial industry has built its risk management of a multi-billion dollar business in CDOs on a simple formula that was developed by a single person in very little time. Is there some truth behind this observation or does it oversimplify? Why 


\section{Total excess loss distribution} (100 names, 200 bps spread)

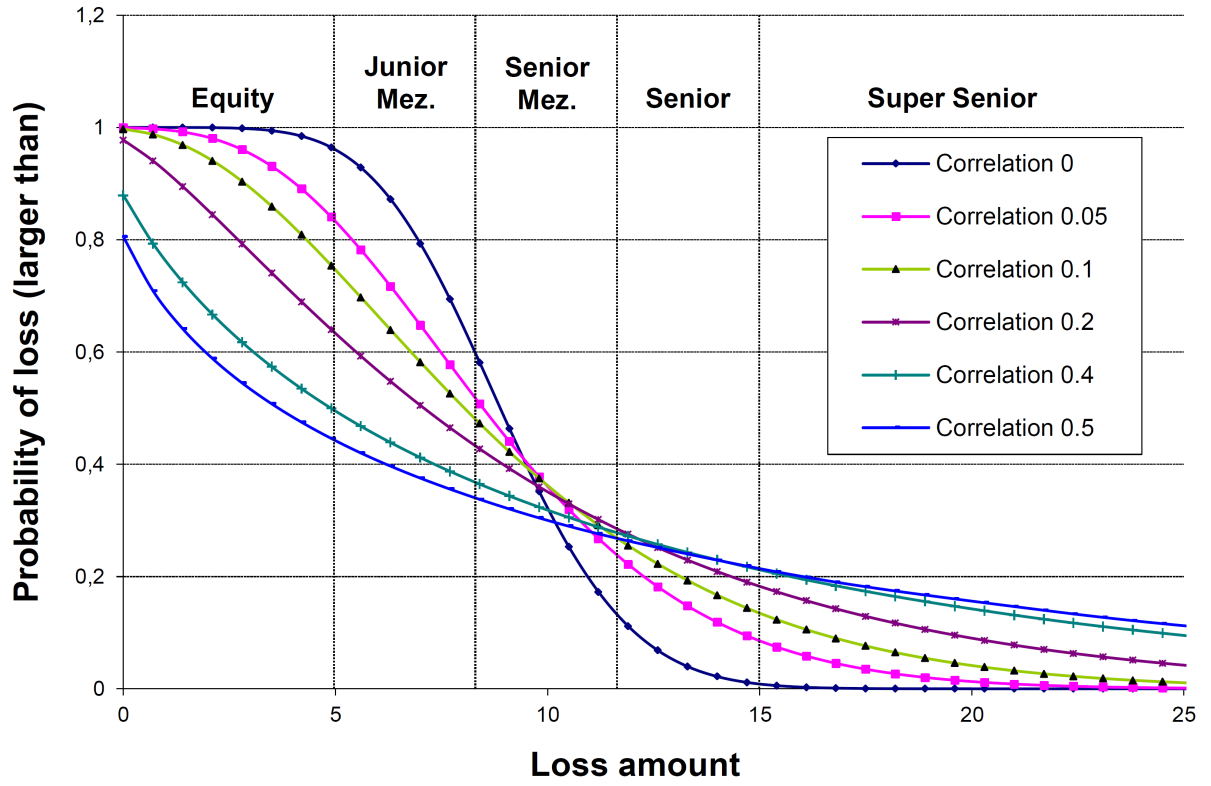

Figure 4: This graph shows the probability that the total portfolio loss is larger than a given amount, which we call excess loss distribution. It also shows the impact of asset correlation on the shape of the excess loss distribution. The expected loss of a CDO tranche is simply the area of the excess loss distribution line, bounded by the attachment and detachment points.

\section{isn't there more research activity on such important topics as dependence modeling or collaborations with academia?}

The Gaussian copula model is still the model used today for credit portfolio risk management and credit portfolio trading. The derivative market develops with or without a model. For example, people started trading options long before the Black-Scholes formula came out. Of course, having a commonly accepted model helps, and sometimes even accelerates the market development for a new product. My paper was published in 2000, even though the model was implemented at CIBC around 1997. But the credit derivatives market and credit portfolio trading started at the beginning of the 1990s.

The early development of the credit derivative market required good modeling to answer a lot of questions and challenges that we encountered in practice. Rating agencies and other practitioners were using different models for rating CBOs and CLOs. For example, the rating agency Moody's used a model called "binomial expansion" for portfolio transaction rating. All three major rating agencies, Moody's, S\&P, and Fitch started adopting the Gaussian copula approach around 2004 or 2005.

Credit portfolio modeling is an interesting, but difficult problem. Defaults are rare events, most of the early techniques used in insurance for rare events were based on an independence assumption. Second, defaults, besides being idiosyncratically driven by an individual firm's situation, are very much driven by macroeconomic factors. The clustering of defaults observed is associated with the economic cycle. Third, for a model to be used for daily trading purpose it must be operationally simple. For example, we need to be able to examine the change in the shape of loss distribution like in Fig. 4. Over the last two decades there have been many alternative models suggested by both academics and industry, each might be used for a certain specific case or a transaction, but none of them has reached the status to replace the Gaussian copula model.

Even though I wrote the first paper on applying copulas explicitly for credit portfolio modeling, this wasn't a single person effort. As I stated before, I had the opportunity to discuss and interact with leading academic researchers and great practitioners, they have played a significant role in forming the idea and crystallized 
its implementation. That was also a period in which many alternative ideas and approaches were published, which helped the development of the idea. Many of them do not necessarily agree with the approach. For example, I have met Professor Darrell Duffie many times, and every time we met he would tell me that "I do not like copulas, but I haven't found a better solution yet." Professor Stuart Turnbull might be the first academic whom I formally presented the idea of using copulas for credit portfolio modeling; he wasn't enthusiastic. But my intention was to solve the practical problems, as I was in the credit derivative trading team, where new products and trading ideas came up on a daily basis. I spent my day time to interact with traders and structurers to understand the practical problems and spent my evening time to read academic and industry research papers to seek for a good solution. I tried to absorb, as much as I could, all academic research and the latest development in the industry in this area.

As a practitioner, I was pretty open to tell technical problems to others, especially academic people, with the hope that we could find better solutions, especially theoretically justified solutions, not just "industry fudge" solutions. I gave talks at top universities such as Columbia, Stanford, Fudan, etc. One time my Citibank boss, Thierry Bollier, and I sat at a table with a group of top academics including Professor Ken French. Thierry posed exactly your question: "Why can't academic people spend more time studying the practical problems such as the credit portfolio modeling problem?” Ken first argued against it, by saying that our problem was not as important as the optimal capital structure problem or equity puzzle problem in Finance, but then conceded that academic people did not know these problems and they did not have data.

To summarize, the Gaussian copula model is still the model used as of this day in KMV and CreditMetrics for credit portfolio risk management as well as in credit derivative trading for portfolio transactions. It is the model also used by all major rating agencies for rating structured credit products. I have explicitly showed the linkage of copulas with these models, but the development in this area has come from many different people.

Traveling back in time equipped with today's experience: How would you change your 2000 paper?

My take on the paper was an engineering approach to solve a practical and thorny problem. I was working at the RiskMetrics Group as a researcher and writing research papers for clients was part of my formal mandate. That explains why I wrote the paper as a working paper for the RiskMetrics Group. I was just summarizing a piece of work that I did a few years back. I am not a prolific author, as I had been a practitioner and my main responsibility was to solve business problems for the company I worked for.

The paper does not have a strong financial economics theory behind it. That explained why I submitted the paper to the Journal of Fixed Income instead of a more academic journal. I have been thinking about this problem for many years and I hope that I will write another paper on the topic and add more theoretical perspectives to the approach. Certain critical issues have not been addressed well by the paper, such as the time horizon and risk measure change issues.

When you submitted your paper to the Journal of Fixed Income, what was the tone of the referee reports?

I didn't get many comments. I guess this is a practitioner's journal and the approach was new, the topic was popular, and it fitted the journal pretty well.

Let's get to the point: Did your model actually destroy Wall Street as allegedly blamed by the famous WIRED Magazine article [18] entitled Recipe for disaster: The formula that killed Wall Street?

The financial crisis started from the subprime crisis. A subprime is a mortgage loan to less creditworthy borrowers. A mortgage loan is subject to two types of risk: prepayment risk and default risk. This is totally different from a corporate bond, which is subject to default risk only. As stated before we use survival times to describe a default event, and then use copulas to construct a joint survival-time distribution. For mortgages, we have to use multiple decrement theory to describe both default and prepayment. From a modeling perspective, it is obvious that you cannot apply a copula model for mortgage modeling. Of course, there were people in the industry trying to "fudge" the modeling by assuming prepayment is prefixed and then each mortgage is only subject to default.

Second, the number of names in an ABS bond or a CDO is quite different. The total number of loans in an ABS could range from a few thousand to several tens of thousands. In corporate credit portfolio modeling we 
usually have at most a few hundred names in the portfolio. The fundamental drivers for default and prepayment in mortgages are interest rates, the house price appreciation index (HPI), as well as the loan borrower's own characteristics such as loan to value ratio, credit score, and the loan properties such as fixed or floating, etc. I was using a model called the "dynamic competing risk model" for subprime modeling in which we modeled both prepayment and default by a Cox model and took the borrowers' creditworthiness and loan characteristics as covariates. It was dynamic, as interest rate and HPI are dynamic variables.

So from a modeling perspective the Gaussian copula model has nothing to do with the subprime crisis. In reality, the Gaussian copula model plus base correlation was used during the financial crisis period for CDX and ITRAXX or any corporate credit portfolio modeling with no major issue at all, and it is still in use, even today. It might have to be enhanced, as people had trouble calibrating the model to the market during the financial crisis.

The author of the article, Felix Salomon, was trying to reach out to me. One day he reached me via Switchboard, when I was working for an investment bank in Beijing and I had to tell him that I could not speak with him due to the company policy. I was surprised by the article, especially its title.

You mentioned the importance of Cox proportional hazard models within credit portfolio modeling. How did you use them?

We were using Cox proportional hazard models with generalized additive model structure for subprime mortgage modeling. This is totally different from credit portfolio models where we have at most a few hundred underlying credit names for each transaction and where we would like to use individual information as much as possible. For ABS bonds with subprime mortgages each bond could have a few thousand and even twenty thousand individual loans as collateral. That is where we would like to use a statistical model to capture the major features of the loans such as FICO score, property types, loan types, and the dynamic drivers such as interest rate and house price index (HPI), etc. We actually use a competing risk model, as each mortgage is subject to different types of risk: prepayment and default risks, the functional forms of the dynamic factor impact on the prepayment and default could be treated using a generalized additive model (GAM) structure. So, the model we used for subprime mortgage modeling is called "Dynamic competing Cox proportional hazard rate model with GAM structure."

Some academic papers give the impression that a simple switch from the Gaussian copula to a more suitable copula family could have prevented the credit crisis. Do you agree?

I do not think so. As stated earlier, the model has little to do with the financial crisis, especially the subprime crisis with the exception that the model might have contributed to the fact that the corporate portfolio credit derivative market developed into a large market.

You can definitely use alternative copulas for a better fit to market prices. This, however, does not mean that you have solved the problem, you simply have made some engineering improvement. Back in 1997 we, the credit derivative trading and quant group at CIBC, had a lot of internal debates about which copula family to use as we had a group of very talented people (Philippe Hatsdadt, Tarek Himmo, Josh Danziger, Gerson Riddy, and Stanley Myint). That was why I listed a few copulas in the paper and showed how to compare different copulas by controlling their rank correlation.

Quants [10,14] at Lehman Brothers initially advocating the Student's t copula to replace the Gaussian copula, as the t copula exhibits asymptotic tail dependence. Nevertheless, [17] show that the t copula provides a worse characterization of the correlation smile than the Gaussian copula approach.

I would encourage people to spend more time and effort studying the theoretical aspects of the model from a financial economics perspective. At this stage, it is still purely an engineering model to solve a complicated problem, but without a theoretical justification. This is pretty sad in the sense that we have been dealing with credit-portfolio problems for more than 20 years without a solid theory. I have had some formal training in financial economics during my postgraduate studies and I become aware of the difference between a theoretical breakthrough and a simple engineering idea.

Considering the financial crisis of $\mathbf{2 0 0 7 +}$ as a very expensive case study in quantitative (mis)management, what should we learn from it to prevent a similar disaster in the future?

I could highlight a few cases where bad models were used, which might have contributed to the financial crisis. I wish we had a standard, public, and commonly adopted subprime mortgage model as popular as 
the Gaussian copula model for corporate credit portfolio modeling, before the financial crisis unfolded. Even during the financial crisis, different firms were valuing the same ABS CDO tranches with strongly different results.

The BET model from Moody's used to be the rating model for all CDO ratings, which is still being used for CLO ratings today. Rating agencies used a "period-by-period" copula model for SIV transactions, which have substantially underestimated the correlation risk in the collateral portfolios. This contributed to a significant percentage of SIV transactions being downgraded, and investors incurred big losses.

I wish more academic people could spend time and effort studying practical problems. I still feel that models are useful tools to solve real world problems. We have come to the age of Big Data and FinTech, but the key elements are still the quantitative methods.

In the public opinion, quantitative models were held to be responsible for mismanagement and their usefulness was questioned? How do you respond to such arguments?

A model is just one part of the whole business. I would suggest that we should always strive to have better models, but importantly to have people who can build the models and understand the shortcomings of a model, and understand the business.

As said by many others, a model is just a tool. You cannot blame a tool. It is the person who uses the tool, who should take the responsibility for misuse of the tool. There are no alternatives to models in many complicated situations. For example, you could predict a stock price to go up or down without using a model. But how about predicting a stock price going up with $80 \%$ probability, and going down with $20 \%$ probability, now you are stating a quantitative model. As we rely more and more on Big Data and make use of machine learning techniques, we are using more models. But it is very important to understand the limitations of models, the assumptions that we make, and the appropriateness of the applicability of the models in practical situations by doing back testing.

Would you please mention some academic papers that appeared after the credit crisis that - if known 10 years earlier - might have prevented the crisis?

I do not know a single paper which could have prevented the financial crisis if written before it. I remember that many years ago a famous applied mathematician once said "Mathematics, in every one of its applied fields, is a good servant, but a bad master." The same could be said about models used in the financial industry. A model is an abstraction of a real-world phenomenon, each model might be able to solve one problem, but there does not exist a "universal model" which could solve all problems in one field. The practical world problems are very often more complex than a typical problem addressed by an academic paper, and the models for these problems are quite sophisticated, too. It is a challenge how to judge if a model really solves the real-world problem or if the model is still far off. You really need people who do understand the problems well, and at the same time, also understand the model well, and who can judge the appropriateness of the model for the problem. As we are using more artificial intelligence or machine learning in our daily decision making, this will become even more important.

There are various books, papers, movies, etc. explaining the financial crisis in retrospective. Which one covers reality closest to how you experienced it?

For more than a year after the financial crisis I didn't want to read anything about it. I was working in Beijing, another country, another economy, and trying to help solving another set of totally different problems.

Then I spent a lot of time with a group of economists, trying to study how a country like China could develop itself and how major global economies interact with each other. The macro perspective has broadened my view about the financial crisis which I couldn't have had if I had continued my work leading a quant group supporting trading business.

I have read a few books, Michael Lewis' books are always a joy to read, the Bernanke, Geithner, Paulson memoirs, "Too Big to Fail." I also watched movies like "Margin Call” and "The Big Short." It is hard to single out one book, article, or movie, which would cover it all; each provides different and interesting perspectives.

After a long period of drought, the $\mathrm{CDO}$ market is recovering. Have we methodologically advanced to the level of being able to control the involved risks nowadays?

The basic technique of pooling assets or risks and slicing and dicing them into different tranches has existed at least a few hundred years. For example, a reinsurance treaty with a deductible and a ceiling, very 

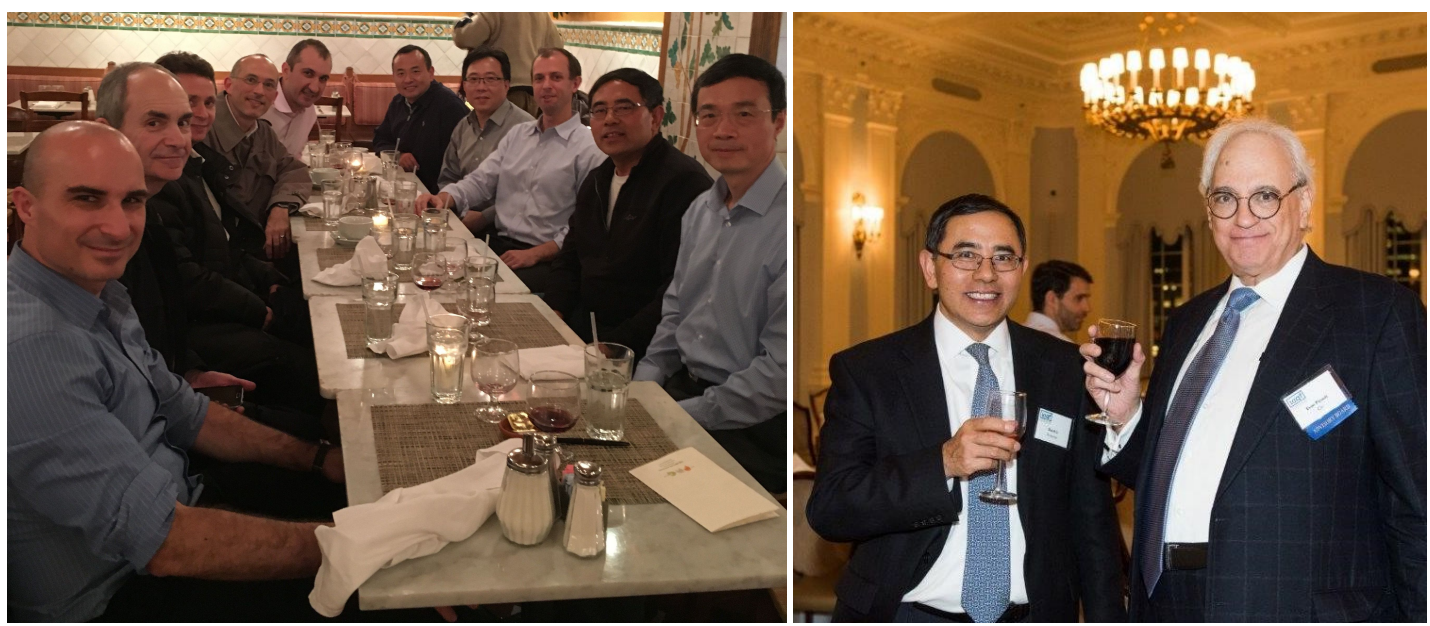

Figure 5: Left: David Li with his collegues from Barclays. Right: David Li with Evan Picoult, a colleague at Citigroup (2016).

much like a CDO tranche, has existed for a few centuries. For the basic CDO market I feel the Gaussian copula model with base correlation and some variation of it should be able to handle it reasonably well. But more fundamental research should be done in this area.

How does it feel to find one's picture on the Wall Street Journal (WSJ) and thus (implicitly) serving as a scapegoat for the financial crisis?

It was not my intention to have public exposure. Mark Whitehouse, the author of the Wall Street article, was introduced to me by Professor Paul Glasserman at Columbia University. Mark was an accomplished journalist who worked for Reuters for many years, before he took a fellowship at Columbia University. He also got an MBA degree while he had his fellowship. In 2005 when the credit market had turmoil, Mark wanted to understand it more, and Paul suggested him to speak with me. I got to know Professor Glasserman in 1995 at a simulation conference in Ottawa, Canada.

I was just helping him to understand the market, expecting at most to get a quote of one or two sentences in an article in the $\mathrm{C}$ section of the Wall Street Journal. But a story about the market, along with some story about people, would be easily accepted for a front-page article in the journal. If you read the article carefully, it was an article around the credit market. That paper was published in the WSJ in Sept. 2005, see [20].

How did the credit crisis affect you professionally? What role did the media coverage play in it?

The financial crisis had an impact on all people who were in the business of structured credit products. Many of my colleagues left the industry, and some for good as the business lost billions of dollars. As a quantitative analyst, I often joked with people that "we have never created any problems, but always strive to solve one or two."

In June 2008, I took a chief risk officer position at a top Chinese investment bank and moved to work in Beijing. I wasn't in Wall Street when the financial crisis fully revealed. I had this strange feeling observing, far from Wall Street, the evolution of the financial crisis, going from the subprime crisis, to the Wall Street crisis, and finally to the financial crisis, and the impact that was felt globally. For example, as a CRO I had to deal with an emergency that a Lehmann Asian subsidiary bought some stock via our brokerage, and couldn't get the transaction settled due to Lehmann's bankruptcy. As someone who worked in the business from where the financial crisis started, I knew the possible impact on the firm or other firms that I either worked for or dealt with. But not many of us expected that large impact on the global economy as we all concentrated on one line of business, and its immediately related businesses. On the other hand, we didn't have a good macro view about the whole situation.

I was consulted very often by our CEO at that time on the financial crisis. He was surprised that I made some correct "predictions" and judgment calls. As a result, I was invited to give talks at a few other financial institutions and government agencies, but all in closed door meetings. 
For the large part I was more concentrated on the new job. I left China in 1987 and returned in 2008. It was a country which experienced a tremendous change over the 21 years while I was studying and working outside of China. The change was unprecedented from a historical perspective with respect to size, pace, and impact. I was happy to get myself reoriented to the country, the culture, and to be part of its development. I had more responsibility and covered different areas such as the whole risk department. I initiated and built up a new quant group from scratch. In addition, I was also managing an IT team to build a global equity trading system with algorithmic trading strategies, the fixed income and risk management systems. I was an adviser to a few government agencies and large corporations, and was involved in some think tanks.

The media coverage, mostly out in 1999, had little impact on me. Our company's PR department had some monitoring capability for any news involved the company's name. I would receive a notice whenever a news article with my name in it came out. For most of the time I just ignored them.

I could not find many interviews with you? Why haven't you spoken to the media before to explain your role in the credit crisis?

I am not a person who likes to have attention from others or the media. On the research side, I am very open to discuss with anyone who might be interested. The financial crisis has been caused by the combination of many forces. It is such a broad topic and I simply happened to work in the business which was blamed for the ignition of the financial crisis. The copula approach to credit portfolio modeling, or a simple version of it the Gaussian copula formula, has been widely used in the industry, which might have contributed to the development of the credit-portfolio business. But from an academic perspective it is just a simple and elegant way to solve a complicated problem, but nothing significant from a theoretical perspective to justify the attention. More work needs to be done here.

Acknowledgements and credits. The authors would like to thank David X. Li for accepting to give this interview and his valuable time. A German version of large parts of this text has already been published in: M. Scherer (2016). Modelle leisten immer noch gute Dinge - Ein Interview mit David X. Li, Risiko Manager (10), 24-30. The authors would like to thank Annette Wenninger for editorial help and Paul Embrechts and Fabrizio Durante for valuable feedback on an earlier draft. The authors acknowledge the financial support of the Department of Statistics and Quantitative Methods of the University of Milano-Bicocca.

\section{References}

[1] Bhatia, M., C. C. Finger, and G. M. Gupton (1997). CreditMetrics ${ }^{T M}-$ Technical Document. J. P. Morgan \& Co, New York. Available at http://www.defaultrisk.com/_pdf6j4/creditmetrics_techdoc.pdf.

[2] Duffie, D. and K. J. Singleton (1999). Modeling term structures of defaultable bonds. Rev. Financ. Stud. 12(4), 687-720.

[3] Durante, F., G. Puccetti, and M. Scherer (2015). Building bridges between mathematics, insurance and finance. Depend. Model. 3(1), 17-28.

[4] Durante, F., G. Puccetti, M. Scherer, and S. Vanduffel (2017). My introduction to copulas. Depend. Model. 5(1), 88-98.

[5] Embrechts, P., A. J. McNeil, and D. Straumann (2002). Correlation and dependence in risk management: Properties and pitfalls. In M. A. H. Dempster (Ed.), Risk Management: Value at Risk and Beyond, pp. 176-223. Cambridge University Press.

[6] Frees, E. W., J. Carriere, and E. A. Valdez (1996). Annuity valuation with dependent mortality. J. Risk Insur. 63(2), $229-261$.

[7] Frees, E. W. and E. A. Valdez (1998). Understanding relationships using copulas. N. Am. Actuar. J. 2(1), 1-25.

[8] Godambe, V. P. (1960). An optimum property of regular maximum likelihood estimation. Ann. Math. Statist. 31(4), $1208-1211$.

[9] Hansen, L. P. (1982). Large sample properties of generalized method of moments estimators. Econometrica 50(4), 10291054.

[10] Jarrow, R. A. and S. M. Turnbull (1995). Pricing derivatives on financial securities subject to credit risk. J. Finance 50(1), 53-85.

[11] Li, D. X. (2000). On default correlation: A copula function approach. J. Fixed Income 9(4), 43-54.

[12] Li, D. X. and H. J. Turtle (2000). Semiparametric ARCH models: An estimating function approach. J. Bus. Econ. Stat. 18(2), 174-186.

[13] Mashal, R. and M. Naldi (2001). Pricing multiname credit derivatives: Heavy tailed hybrid approach. Available at http://www.faculty.idc.ac.il/roy/Pub/Mashal_Naldi_Hybrid.pdf.

[14] Mashal, R., M. Naldi, and A. Zeevi (2003). Extreme events and multi-name credit derivatives. In J. Gregory (Ed.), Credit Derivatives: The Definitive Guide, pp. 313-338. Risk Books, New York. 
[15] Merton, R. C. (1974). On the pricing of corporate debt: The risk structure of interest rates. J. Finance 29(2), 449-470.

[16] Nelsen, R. B. (2006). An Introduction to Copulas. Second edition. Springer, New York.

[17] O’Kane, D. (2008). Modelling Single-name and Multi-name Credit Derivatives. Second edition. John Wiley \& Sons, Chichester.

[18] Salmon, F. (2012). The formula that killed Wall Street. Significance 9(1), 16-20.

[19] Wang, S. (1998). Aggregation of correlated risk portfolios: Models and algorithms. In Proceedings of the Casualty Actuarial Society, pp. 848-939. United Book Press, Baltimore MD.

[20] Whitehouse, M. (2005). Slices of risk: How a formula ignited market that burned some big investors. The Wall Street Journal.

[21] Wilde, T. (1997). CreditRisk ${ }^{+}$: A Credit Risk Management Framework. Credit Suisse First Boston International, London. Available at http://www.csfb.com/institutional/research/assets/creditrisk.pdf.

[22] Wilson, T. C. (1998). Portfolio credit risk. FRBNY Economic Policy Review, 71-82. 